\title{
Forests on thawing permafrost: fragmentation, edge effects, and net forest loss
}

\author{
JENNIFER L. BALTZER*†, TYLER VENESS †, LAURA E. CHASMER \\ ANASTASIA E. SNIDERHAN* and WILLIAM L. QUINTON† \\ *Biology Department, Wilfrid Laurier University, 75 University Ave. W, Waterloo, ON, Canada N2L 3C5, †Centre for Cold \\ Regions \& Water Science, Wilfrid Laurier University, 75 University Ave. W, Waterloo, ON, Canada N2L 3C5
}

\begin{abstract}
Much of the world's boreal forest occurs on permafrost (perennially cryotic ground). As such, changes in permafrost conditions have implications for forest function and, within the zone of discontinuous permafrost (30-80\% permafrost in areal extent), distribution. Here, forested peat plateaus underlain by permafrost are elevated above the surrounding permafrost-free wetlands; as permafrost thaws, ground surface subsidence leads to waterlogging at forest margins. Within the North American subarctic, recent warming has produced rapid, widespread permafrost thaw and corresponding forest loss. Although permafrost thaw-induced forest loss provides a natural analogue to deforestation occurring in more southerly locations, we know little about how fragmentation relates to subsequent permafrost thaw and forest loss or the role of changing conditions at the edges of forested plateaus. We address these knowledge gaps by (i) examining the relationship of forest loss to the degree of fragmentation in a boreal peatland in the Northwest Territories, Canada; and (ii) quantifying associated biotic and abiotic changes occurring across forestwetland transitions and extending into the forested plateaus (i.e., edge effects). We demonstrate that the rate of forest loss correlates positively with the degree of fragmentation as quantified by perimeter to area ratio of peat plateaus (edge : area). Changes in depth of seasonal thaw, soil moisture, and effective leaf area index $\left(\mathrm{LAI}_{\mathrm{e}}\right)$ penetrated the plateau forests by 3-15 m. Water uptake by trees was sevenfold greater in the plateau interior than at the edges with direct implications for tree radial growth. A negative relationship existed between $\mathrm{LAI}_{e}$ and soil moisture, suggesting that changes in vegetation physiological function may contribute to changing edge conditions while simultaneously being affected by these changes. Enhancing our understanding of mechanisms contributing to differential rates of permafrost thaw and associated forest loss is critical for predicting future interactions between the land surface processes and the climate system in high-latitude regions.
\end{abstract}

Keywords: boreal forest loss, discontinuous permafrost, global warming, Mackenzie river basin, northwest territories, permafrost thaw, Picea mariana, subarctic

Received 15 May 2013 and accepted 30 July 2013

\section{Introduction}

Permafrost (i.e., perennially cryotic) ground occupies $16 \%$ of the global soil area (Tarnocai et al., 2009). In Canada, peatlands comprise 1.14 million $\mathrm{km}^{2}, 37 \%$ of which are perennially cryotic (Tarnocai, 2006). Boreal peatlands are second only to tropical forests in terms of the carbon they store (Gorham, 1991; Frolking et al., 2011), and thus changes in the functioning of this system have global consequences (Soja et al., 2007; Camill et al., 2010). In the zone of sporadic to discontinuous permafrost (Heginbottom, 2002), permafrost distribution is often a strong determinant of forest cover (e.g., Quinton et al., 2011). Permafrost formed in peatlands within this region is ice-rich, resulting in a ground surface that is elevated $0.5-1.5 \mathrm{~m}$ above surrounding

Correspondence: Jennifer L. Baltzer, tel: +1 5198840710 ext. 4188, fax +1 519746 0677, e-mail: jbaltzer@wlu.ca wetlands (estimated from light detection and ranging [LiDAR] at Scotty Creek in 2010; Quinton et al., 2011), often referred to as peat plateaus. As a result, a hydraulic gradient exists between the forested areas and the surrounding wetlands (bogs and fens) so that the former are relatively well drained and contribute runoff to adjacent wetlands (Quinton et al., 2009). However, as the permafrost in this region is relatively warm (ca. $-0.2{ }^{\circ} \mathrm{C}$; Smith et al., 2005) and thin (5-15 m; Quinton et al., 2009), it is susceptible not only to thaw but also to complete disappearance. Permafrost thaw in peatlands typically leads to thermokarst (i.e., subsidence of the ground surface) with dramatic implications for the vegetation and hydrology of the system (e.g., Camill, 1999; Yoshikawa \& Hinzman, 2003) and carbon storage and release (Turetsky et al., 2007). Tarnocai (2006) estimated that as much as $87 \%$ of Canada's ca. $421500 \mathrm{~km}^{2}$ of peatlands that overlay permafrost will be severely impacted by climate warming-induced permafrost 
thaw and corresponding increases in surface wetness. There is widespread evidence of such changes along North America's southern margin of permafrost (Thie, 1974; Camill et al., 2001; Jorgenson \& Osterkamp, 2005; Quinton et al., 2011). However, in Eurasia, such changes appear to be less prevalent (but see Christensen et al., 2004) perhaps due to lower proportional representation by discontinuous permafrost in the permafrost landscape and/or lower prevalence of peatlands along the southern margin or permafrost (Anisimov \& Reneva, 2006; Tarnocai et al., 2009).

As thermokarst progresses, the forests supported by permafrost plateaus are susceptible to degradation and loss (Camill et al., 2001; Camill, 2005). Picea mariana, the dominant tree species on peat plateaus, is unable to tolerate conditions of waterlogging (Islam \& Macdonald, 2004). Waterlogging results in conditions of low oxygen concentrations in the rooting zone, which affects many plant physiological processes including metabolism, carbon uptake, transpiration, and nitrogen metabolism (reviewed in Drew, 1997). Most conifers have limited capacity for oxygen transport to ameliorate these effects (Kozlowski, 1982). As a consequence, the distribution of these forests corresponds very closely with the distribution of permafrost (Quinton et al., 2011).

Geological setting and climate are major determinants of the spatial extent of permafrost in the discontinuous zone (reviewed in Jorgenson et al., 2010). Although the geological setting is considered stable over the time scale of centuries, the climate can fluctuate on shorter time scales, causing whole ecosystems to move toward new equilibrium points, although complex ecosystem feedbacks, nonlinear interactions and disturbance (e.g., fire, resource extraction) can affect the trajectory of these changes (Jorgenson et al., 2010; Turetsky et al., 2011). Indeed, there is increasing evidence throughout the circumpolar zone of discontinuous permafrost that the rates of permafrost aggradation and degradation are not in a state of equilibrium (Zoltai, 1993), and that 20th century warming has produced rapid and widespread lateral permafrost thaw, and a corresponding net forest loss (Thie, 1974; Beilman \& Robinson, 2003; Jorgenson et al., 2006).

\section{Permafrost-driven forest fragments}

In peatlands in the discontinuous permafrost zone, forests exist on permafrost plateaus of variable sizes while permafrost-free wetlands are non-forested or sparsely treed. The transition between forest and wetlands is typically stark, transitioning over short distances (i.e., 1-2 m) from an open, short-statured forest often dominated by P. mariana to Sphagnum-dominated flat bogs with minimal aboveground woody biomass or channel fens with a floating peat mat. Little is known about the abiotic conditions at these boundaries (but see O'Donnell et al., 2012), the depth of penetration of edge-related abiotic changes into the plateau forest, or how fragmentation and associated edge effects impact the rate and pattern of permafrost thaw and associated forest dynamics. Addressing this knowledge gap would provide a natural analogue to forest fragmentation caused by anthropogenic deforestation at lower latitudes where impacts have been well documented, particularly in tropical forest systems (e.g., Laurance et al., 2002; for general fragmentation review see Kupfer et al., 2006).

There is ample documentation of a range of impacts of forest fragmentation that leads to continued degradation or decay of the remaining forest fragments. For example, changes in the microenvironmental conditions at the edges of more southerly forests (here we define the forest 'edge' to mean the portion of the forest affected by its proximity to the true linear edge and for clarity will refer to this as the transitional forest) have been shown to result in increased drought stress and tree mortality due to higher vapor pressure deficits, temperatures, and incident radiation (reviewed in Harper et al., 2005; Kupfer et al., 2006). As is the case for forest fragments resulting from anthropogenic deforestation, there is also a range of dramatic changes that occur at the edges of the forested peat plateau fragments. Evident changes in the edge or transitional forest include the thickening of the active (i.e., seasonally thawed) layer, which can result in the complete loss of permafrost from a local area within a plateau. Other changes include ground surface subsidence and concomitant increases of both the water table elevation and the nearsurface (i.e., $\leq 0.1 \mathrm{~m}$ ) soil moisture content, increased insolation at the ground surface, and changes to the soil thermal properties (Jorgenson et al., 2010; O'Donnell et al., 2012; Quinton \& Baltzer, 2013). These, among other changes result in dramatic plant community transitions over short temporal and spatial scales (Beilman, 2001; Camill et al., 2001). Furthermore, because the permafrost substrate supporting the forests in this region is highly susceptible to thaw, there is good reason to suspect that the greater the exposure of plateaus to edge conditions, the more rapid the subsequent decay of fragments will be for the reasons explained above.

Our overall objective is to improve our understanding of ongoing permafrost thaw and the resulting forest loss in the context of landscape fragmentation. Specifically, we aim to: (i) determine whether the degree of fragmentation of peat plateaus influences the rates of permafrost thaw and consequently, forest loss with the specific hypothesis that fragmented plateaus will change more rapidly than non-fragmented ones; and (ii) identify a range of abiotic and biotic factors that may contribute to 
permafrost thaw and forest loss on peat plateaus. Understanding how the degree of fragmentation of permafrost plateaus impacts the rate and pattern of thaw and associated forest loss is critical to understanding the trajectories of these systems as warming progresses. Furthermore, quantifying the distance of edge influence into the plateau forests will allow for an improved understanding and prediction of changes in forest productivity in this large region of the boreal forest.

\section{Materials and methods}

\section{Study site}

The Scotty Creek watershed $\left(61^{\circ} 18^{\prime} \mathrm{N} ; 121^{\circ} 18^{\prime} \mathrm{W}\right)$ is a $152 \mathrm{~km}^{2}$ drainage basin in the lower Liard River Valley in the Northwest Territories, Canada. The basin is located in the zone of extensive discontinuous permafrost characterized by a mosaic of peat plateaus, collapse scar bogs, and channel fens (Quinton et al., 2009), typical of the southern region of permafrost (Kwong \& Gan, 1994). The mean (1971-2000) annual air temperature at the Fort Simpson weather station, $50 \mathrm{~km}$ North of Scotty Creek is $-3.2{ }^{\circ} \mathrm{C}$ with January and July average air temperatures of -25.4 and $17.2{ }^{\circ} \mathrm{C}$, respectively. The site receives a total annual precipitation of $369 \mathrm{~mm}$ with $170 \mathrm{~mm}$ of that coming in the form of snow (Environment Canada, 2007). While precipitation has remained relatively stable, mean annual air temperatures at Scotty Creek have increased by ca. $2{ }^{\circ} \mathrm{C}$ over the last 50 years (Quinton et al., 2009).

\section{Remote sensing of permafrost thaw}

For this analysis, the three sets of data used were as follows: (i) a single aerial photograph of the study area $(0.53 \mathrm{~m}$ pixel resolution) acquired on June 12, 1977; (ii) an IKONOS multispectral satellite image (4 $\mathrm{m}$ pixel resolution) acquired September 4, 2000; and (iv) a WorldView2 image (1.4 m pixel resolution) acquired for the Scotty Creek watershed on August 31, 2010. The 2010 dataset was acquired ca. 2 weeks following an airborne LiDAR survey. Methods used to process remotely sensed data are reported in Chasmer et al. (2010, 2011a).

To examine the influence of plateau fragmentation on rates of vegetation change (as a proxy for permafrost change), seven $500 \times 500 \mathrm{~m}$ areas of interest (AOIs) representing the broad range of peat plateau fragmentation were selected and individually subset from the remote sensing data. AOIs also contain similar topographic and vegetation structural characteristics so that fragmentation could be assessed equally (without additional influences). Peat plateaus were first identified using a LiDAR and WorldView2 fusion classification based on terrain derivatives, vegetation structural attributes, smoothing/aggregation filters, and spectral variability (dissimilarity filters) (Surfer; Golden Software Inc., Golden, CO, USA; ArcGIS; ESRI, Redlands, CA, USA; and Geomatica; PCI Inc., Ottawa, ON, Canada) (L. Chasmer, C. Hopkinson, T. Veness, W. Quinton \& J. Baltzer, unpublished data). Plateau shapes within the seven AOIs vary from relatively large 'intact' plateaus with few internal bogs and less complex edges, to those more 'fragmented' plateaus containing isolated bogs, large gaps in forest cover and highly complex, rough edges at the plateau/bog margin.

Plateau edges in 1977, 2000, and 2010 were manually digitized by the authors at the land cover margins based on spectrally 'bright' graminoids found in bogs vs. spectrally 'dark' P. mariana trees found on plateaus (delineation errors are discussed in Chasmer et al., 2010). The fusion classification methodology was not applied to other historical datasets due to (i) lack of historical LiDAR data; and (ii) an inability to define spectral classes within single band aerial photography. It was therefore simply used as a method for plateau identification and vegetation structural and topographic control, such that comparable plateau characteristics did not vary among AOIs.

Within each AOI, all pixels were classified as either plateau or wetland, thus the total plateau area as well as the proportional plateau area were available. Annual rates of forest loss and assumed permafrost thaw for each time period were calculated by taking the difference in proportional plateau area between two time periods and dividing by the number of years between the two end points of each period. Total edge length (including the edges of interior bogs on a plateau) was quantified using ArcGIS (ESRI) and a spatial pattern analysis program, FragStats (McGarigal \& Marks, 1995). The edge to area ratio (edge : area) was calculated for each of the seven areas of interest and three time periods.

\section{Biotic responses}

Although there is a wide range of biotic changes across the wetland - forest transition in these systems, we limit our focus to responses of the dominant tree species, $P$. mariana to changing conditions at the forest edge. To this end, we quantified sap flow in the root systems of trees at forest edges and interiors as well as radial growth of trees growing under the same conditions. Sap flow was measured using Heat Ratio Method sap flow sensors (ICT International, Tamsworth, Australia) in the roots of 12 trees: six on plateau edges and six in the interior. All trees were of similar size $(6.9-7.9 \mathrm{~cm}$ diameter at breast height; 4.6-8.0 m height with live crown ratios greater than 50\%) thereby avoiding size-related biases in sapwood area and sap flow estimates, with the majority of the canopy having healthy foliage. Trees with any apparent damage to the stem were avoided. We installed sensors on major roots ranging in diameter from 5.5 to $8.5 \mathrm{~cm}$ near the base of the stem and above any branching points in the root. All roots were at least $10 \mathrm{~cm}$ below the ground surface. For the trees on the plateau edges, roots on the bog side of the tree were measured. Bog side roots were measured both for consistency among sampled trees and to ensure that at least part of the sampled root was exposed to degraded, waterlogged conditions. Here we report daily maximum sap fluxes averaged for each individual from July 10-20, 2012 at which point soils in the rooting zone were completely thawed (J.L. Baltzer, personal observation) and root function was thus presumably optimized. During 2012, core samples were taken at breast height (1.3 $\mathrm{m}$ above ground) from 26 living trees with a 
greater than $7 \mathrm{~cm}$ diameter at breast height (range: 7.3$10.5 \mathrm{~cm} \mathrm{DBH})$. Thirteen of the trees sampled are on the edge of a permafrost plateau/bog interface, and the remaining sampled from the interior of the plateau (greater than $10 \mathrm{~m}$ from nearest edge). There was no difference in the size of trees sampled between edge and interior locations. Cores were handled and prepared using traditional dendrochronology techniques as described in Speer (2010). Ring widths were measured to an accuracy of $0.001 \mathrm{~mm}$ in CooRecorder (Cybis Elektronik \& Data $\mathrm{AB}$, http://cybis-elektronik-data-ab.software.informer. com), and the dating accuracy was verified through crossdating to the site's master chronology using Cofecha. Data on 2011 radial growth are presented being the most recent complete year of growth in the core samples. Average age of the cored trees was 127 years (range: 83-162 years).

\section{Abiotic responses}

In 2011, 10 transects were established which traversed entire plateaus and extended into the wetlands on either side. Along each transect, end of winter snow depth (March 24-30, 2011), depth-integrated soil moisture from 0 to $5 \mathrm{~cm}$ (site-calibrated Delta-T Theta-Probe ML2x (Delta-T Devices, Cambridge, UK); measured in tandem with end of summer thaw depth), end of summer frost table depth (depth to refusal of a graduated steel rod measured on August 29, 2011), vegetation cover fraction, and effective leaf area index (hereafter $\mathrm{LAI}_{e}$ ) were measured at $1-3 \mathrm{~m}$ intervals and geographically located using a Leica (Leica Geosystems Inc., Norcross, GA, USA) SR530 RTK (realtime kinematic) differential GPS system (system accuracy = $\pm 0.02 \mathrm{~m}$ ). Vegetation cover fraction and $\mathrm{LAI}_{\mathrm{e}}$ were quantified using hemispherical photography at every $6 \mathrm{~m}$ along each transect and at all transition points during diffuse conditions on May 10, 2011. Level photographs were taken using a Canon EOS Rebel XSI digital camera (Canon Inc., Melville, NY, USA) with a full 180-degree fisheye lens (Sigma $4.55 \mathrm{~mm}$ for Canon, Rokonkoma, NY, USA), and oriented such that the top of the photograph faced north in all photos. Photographs were taken at $2 \mathrm{f}$-stops below automatic exposure (Zhang et al., 2005) and at a height of ca. $35 \mathrm{~cm}$ above the ground surface so that lower branches intercepting incident radiation would be included as these are important for permafrost thaw (Chasmer et al., 2011b). A binary classification (sky vs. vegetation) was performed on annulus rings 1-6 (to reduce influence of high extinction coefficients at lower solar azimuth angles and potential autocorrelation between sampling locations) using CanEye (CanEye V5.0; INRA, Avignon, France) to estimate vegetation cover fraction and $\mathrm{LAI}_{\mathrm{e}}$. On each transect, the point of transition from forest to wetland was noted and measured again facilitating distance from edge metrics. Here, maximum winter snow depth (early March measurements), end of summer ground thaw depth, surface volumetric soil moisture, vegetation cover fraction, and $\mathrm{LAI}_{\mathrm{e}}$ will be presented as a function of distance from the plateau edge.

Measurements of vertical profiles of soil temperature were carried out on a single plateau and the adjacent bog and channel fen to quantify differences in soil thermal properties that might be contributing to thaw processes at plateau edges. For the plateau profile, a pit was excavated that extended to the bottom of the thawed layer on August 20, 2001. At the time of installation, the depth of thaw was $0.7 \mathrm{~m}$, and the thermistors (Campbell Scientific, 107, Edmonton, AB, Canada) were installed at $0.05,0.1,0.15,0.2,0.25,0.3,0.4,0.5,0.6$, and $0.7 \mathrm{~m}$ depths. Less intensive profiles were established in the bog and the fen with measurement depths being 0.1 and $0.3 \mathrm{~m}$, and $0.1,0.5$, and $1.3 \mathrm{~m}$, respectively. These sensors have since been measuring continuously. We present data from 2007 as this year provided the most complete dataset for all three profiles (plateau, bog, and fen). At this site, the organic layer is very deep (4-5 m depth; A.F. McClymont, M. Hayashi \& L.R. Bentley, unpublished data) thus all temperature data presented are for organic soils.

\section{Statistical analyses}

Differences in the rates of thaw between time periods (19772000 vs. 2000-2010) were quantified using analysis of variance (ANOVA) with the annualized rates of thaw as the dependent variable and the time period the independent variable. The relationship between rate of thaw (1977-2010) and the initial edge : area (1977) was determined using least-squares regression with edge : area as the predictor. To assess the distance of edge influence into the plateau forests, we used distance from the plateau edge as a predictor of the following variables: end of summer frost table depth, soil moisture, snow depth, vegetation cover fraction, and $\mathrm{LAI}_{\mathrm{e}}$. These relationships were fit using nonlinear regression models (nls function). We used this method to test whether edge conditions asymptotically approach plateau interior values with increasing distance from the edge, which has been demonstrated in other systems (e.g., Ewers \& Didham, 2008). All statistical analyses were conducted using R (v 2.13.1; R Development Core Team, 2011).

\section{Results}

\section{Rates and drivers of permafrost thaw}

Our findings indicate permafrost thaw and forest loss with the mean annual losses of $0.26 \pm 0.03 \%$ between 1977 and 2010 (Fig. 1; Table 1). Thus, over this time period, $8.6 \pm 0.7 \%$ (mean and SE across seven AOIs) of the total forested plateau area examined was converted to wetland. Furthermore, annualized rates of forest loss nearly tripled between the two time intervals (19772000 and 2000-2010; Figs 1 and 2; Table 1). Across the seven AOIs, rates of permafrost thaw-induced forest loss were significantly related to the initial edge : area. AOIs with greater edge : area had greater rates of permafrost thaw and forest loss (Fig. 3).

\section{Edge effects}

Distance from the plateau edge was a significant predictor of end of season thaw depth, surface soil moisture, and $\mathrm{LAI}_{\mathrm{e}}$ (Table 2; Fig. 4). There was no 
$1977(0.54)$

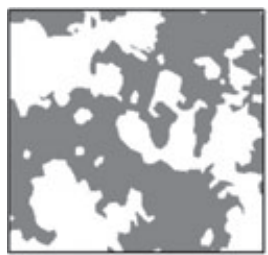

$1977(0.65)$

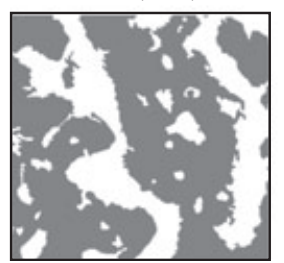

$2000(0.46)$

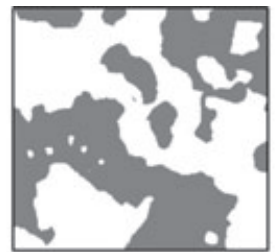

$2000(0.63)$

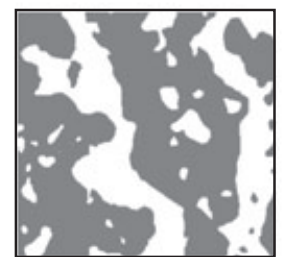

$2010(0.41)$

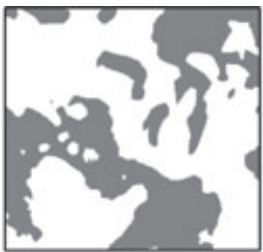

$2010(0.58)$

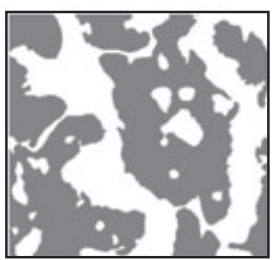

$\stackrel{\Delta}{\mathbf{N}}$

Legend

Wetlands

Forest

Fig. 1 Two of seven $500 \times 500 \mathrm{~m}$ areas of interest showing permafrost and forest cover in 1977, 2000, and 2010. The top row corresponds with the sample area with the highest rates of thaw as well as the greatest edge to area ratio in 1977, while the lower row corresponds with the sample area with lowest rates of thaw and one of the lowest edge : area. Note that white areas correspond to wetland while dark gray areas correspond to forests on permafrost. Summary statistics for all areas of interest (AOIs) are provided in Table 1.

Table 1 Proportional coverage of plateaus within each area of interest (AOI) for the three time periods. Rates of permafrost thaw and forest loss $\left(\% \mathrm{yr}^{-1}\right)$ for each time period $(1977-2000,2000-2010)$ and for the entire study period (1977-2010)

\begin{tabular}{lllllll}
\hline $\begin{array}{l}\text { Proportional coverage } \\
\text { AOI }\end{array}$ & 1977 & 2000 & 2010 & $\begin{array}{l}\text { Rate of loss } \\
1977-2000\end{array}$ & $2000-2010$ & $1977-2010$ \\
\hline 1 & 0.47 & 0.44 & 0.38 & 0.15 & 0.57 & 0.32 \\
2 & 0.67 & 0.64 & 0.61 & 0.13 & 0.51 & 0.19 \\
3 & 0.54 & 0.46 & 0.41 & 0.33 & 0.26 & 0.38 \\
4 & 0.62 & 0.58 & 0.56 & 0.16 & 0.63 & 0.19 \\
5 & 0.67 & 0.63 & 0.57 & 0.17 & 0.46 & 0.19 \\
6 & 0.65 & 0.63 & 0.58 & 0.07 & 0.51 & 0.28 \\
7 & 0.64 & 0.60 & 0.55 & 0.18 & &
\end{tabular}

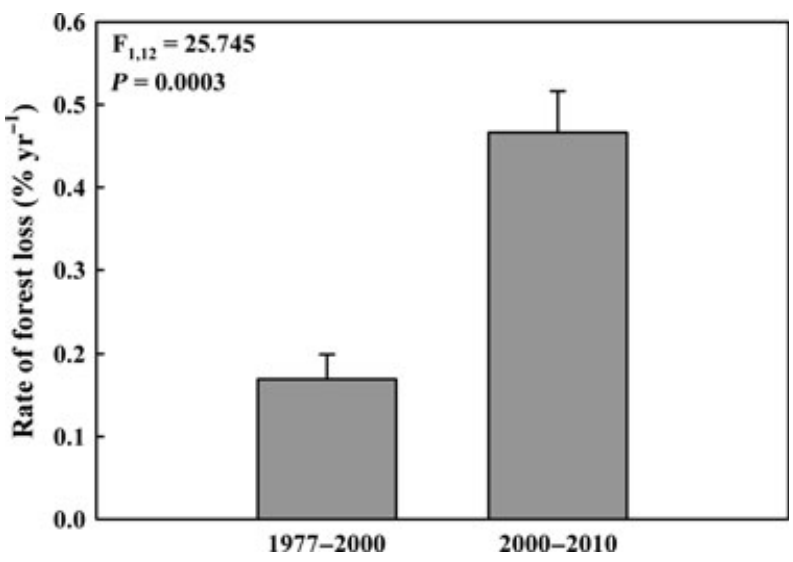

Fig. 2 Annual rates $( \pm \mathrm{SE})$ of permafrost thaw-induced forest loss in two time periods (1977-2000, 2000-2010). Analysis of variance results are provided in the panel.

relationship of vegetation cover fraction or snow depth with distance from edge (Table 2). With increasing distance into the forest from the plateau edge, end of season thaw depth decreased as indicated by frost table

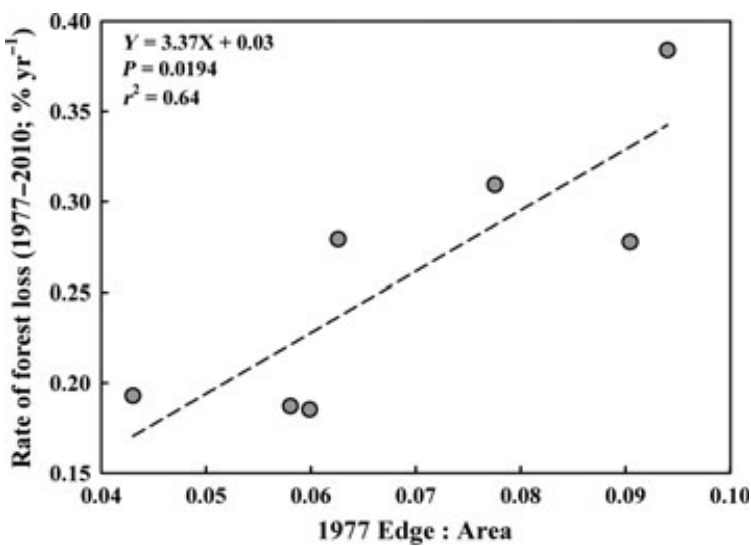

Fig. 3 The relationship between annual rates of permafrost thaw between 1977 and 2010 and the 1977 edge to area ratio. Results of type I regression analysis are provided in the panel and the relationship indicated with the dashed line.

positions closer to the ground surface (Fig. 4a). A rapid decrease in the end of season thaw depth to between 10 and $15 \mathrm{~m}$ into the plateau is evident at which the frost 
Table 2 Nonlinear regression relationships between maximum thaw depth (Thaw), volumetric soil moisture (VWC), vegetation cover fraction (FracCov), effective LAI ( $\mathrm{LAI}_{\mathrm{e}}$ ), or snow depth (snow), and unbinned values for distance from the edge of the plateau (Dist)

\begin{tabular}{llll}
\hline Variable & Relationship & $a$ & $b$ \\
\hline Thaw & $46.1 \times \log$ (Dist +1$)-130.5$ & $t=3.88, P=0.0002$ & $t=-9.2, P<0.0001$ \\
VWC & $-8.9 \times \log$ (Dist +1$)+43.9$ & $t=-2.21, P=0.0285$ & $t=43.9, P<0.0001$ \\
FracCov & $0.04 \times \log$ (Dist +1$)+0.28$ & $t=1.16, P=0.2490$ & $t=6.24, P<0.0001$ \\
LAI $_{\mathrm{e}}$ & $0.34 \times \log$ (Dist +1$)+0.53$ & $t=2.78, P=0.0070$ & $t=3.73, P=0.0004$ \\
Snow & $3.92 \times \log$ (Dist +1$)+75.9$ & $t=0.62, P=0.5370$ & $t=10.14, P<0.0001$ \\
\hline
\end{tabular}

table depth stabilizes between 50 and $60 \mathrm{~cm}$ (Fig. 4a). Surface soil moisture values show a similar trend with surface soil moisture decreasing rapidly with distance from the edge but the inflection point in the relationship occurred much closer to the edges with soil moisture values stabilizing at $30 \%$ ca. $3 \mathrm{~m}$ from the edge (Fig. $4 \mathrm{~b}$ ). $\mathrm{LAI}_{\mathrm{e}}$ increased from the edge to ca. $6 \mathrm{~m}$ onto the plateau (Fig. 4c). Neither snow cover nor fractional vegetation cover showed significant relationships with distance from the edge when bog values were not included (Table 2). Sap flow in the roots of interior trees was significantly greater than trees occurring at forest edges (Fig. 5a). Some roots measured on edge trees had virtually ceased all sap flow resulting in large differences in water uptake between edge and interior positions on the plateau. This reduced physiological function was borne out in terms of radial growth as well with interior trees having significantly higher growth rates than those growing near plateau edges (Fig. 5b). Substantial differences existed in the vertical soil temperature profiles between plateaus and bogs or fens (Fig. 6). Specifically, on the plateaus, surface $(0-10 \mathrm{~cm})$ soil temperatures are relatively warm during the growing season but reach much lower minimum temperatures during the winter months when compared with either bogs or fens. In contrast, bogs and fens show much less variable seasonal changes at the same shallow depths and showed little variation among measured depths (Fig. 6). Furthermore, bogs and fens maintain soil temperatures close to $0{ }^{\circ} \mathrm{C}$ throughout the winter months. At greater depths (30 and $50 \mathrm{~cm}$ ), plateau soils were consistently cooler during the growing season compared to those in bogs or fens. Deeper soil layers on the plateaus are closer to permafrost giving rise to a rapid thermal gradient through the shallow active (seasonally thawed) layer.

\section{Discussion}

\section{Permafrost thaw and forest loss}

High-latitude forests are considered temperaturelimited systems and as such predictions of boreal forest responses to climate warming include the potential for forest expansion and productivity (reviewed in Lloyd \& Bunn, 2007; Soja et al., 2007). In contrast to predictions, it has been shown repeatedly that the broad circumpolar swath of forest on discontinuous permafrost has been shrinking due to permafrost thaw (Thie, 1974; Beilman \& Robinson, 2003; Christensen et al., 2004; Jorgenson \& Osterkamp, 2005). Previous studies at Scotty Creek examining a single area repeatedly from 1947 to 2008 have provided strong evidence of permafrost thaw at this site (Chasmer et al., 2011a; Quinton et al., 2011). Camill (2005) demonstrated comparable increases in permafrost loss rates at the southern extent of discontinuous permafrost in Manitoba, Canada, due to regional climate warming. Similar warming trends are apparent at Scotty Creek and the wider southern margin of discontinuous permafrost (see Study site in Methods; Kwong \& Gan, 1994; Quinton et al., 2009). The present results advance our understanding of this process of warming-induced permafrost loss and resulting forest alteration and loss by: (i) quantifying the role of plateau fragmentation on rates of permafrost thaw and forest loss; and (ii) examining a range of edge effects that may be contributing to the relationship between degree of fragmentation and rates of permafrost thaw and forest loss.

\section{Fragmentation impacts on permafrost thaw and forest loss}

Forest fragmentation results in increased edge length and therefore increased exposure of remaining forest to edge effects, including changes to the microenvironment, biotic responses, increased disturbance, and/or alterations to the ecological function of the remaining forest (reviewed in Kupfer et al., 2006). Here we provide evidence that the degree of fragmentation impacts the rate of forest loss in a high-latitude boreal forest occurring on discontinuous permafrost. Edge : area of the seven sampled areas described a significant amount of variation in forest loss quantified for seven AOIs in the Scotty Creek watershed (Fig. 3). Increased edge exposure has been suggested in previous examinations 

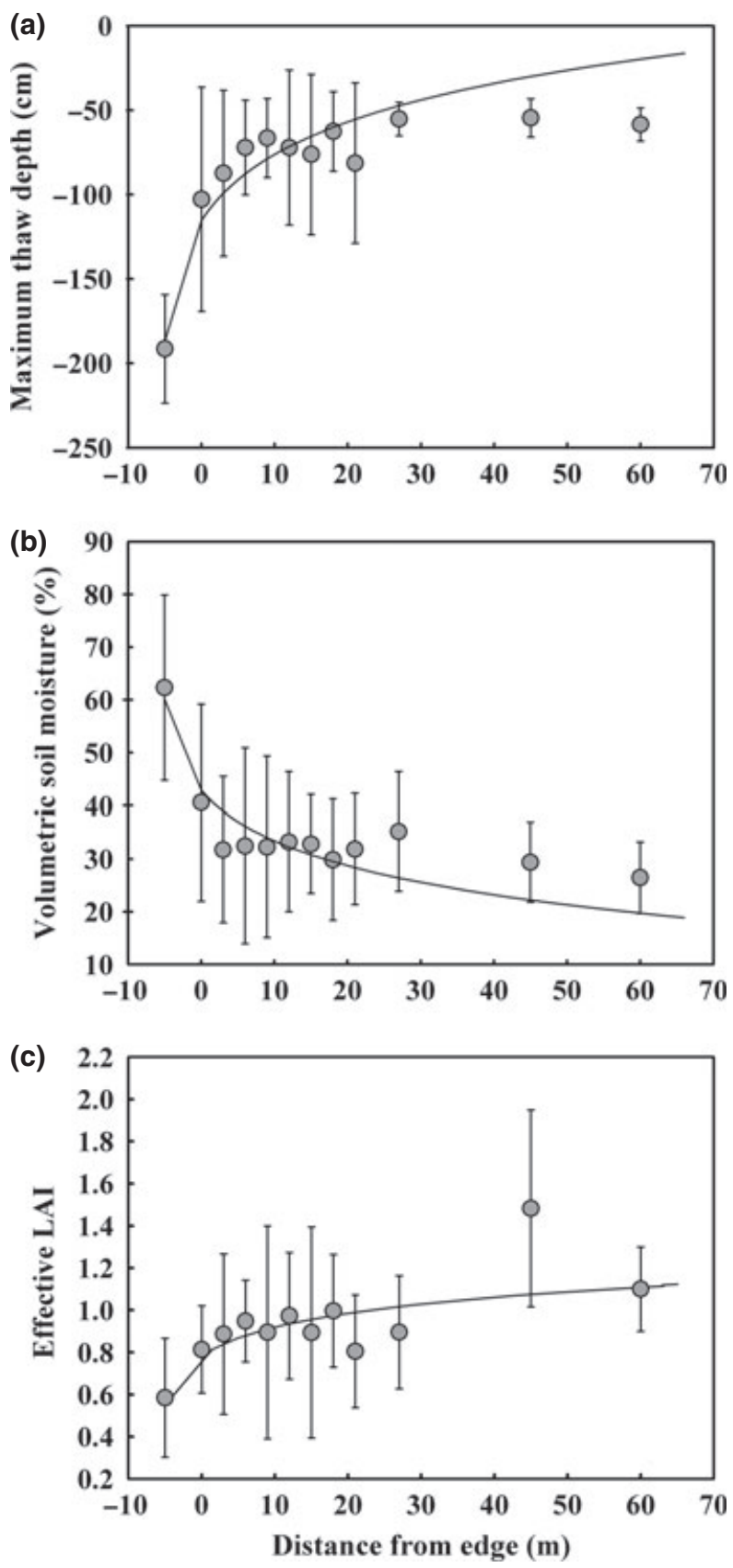

Fig. 4 Relationships of (a) end of season thaw depth, (b) integrated surface volumetric soil moisture, and (c) effective leaf area index $\left(\mathrm{LAI}_{\mathrm{e}}\right)$ as a function of distance from forest-wetland interfaces. Error bars indicate the one SD for binned categories. Nonlinear regression lines indicate significant relationships between fitted to the complete continuous dataset and can be found in Table 2.

of permafrost thaw in the discontinuous zone (Payette et al., 2004; Chasmer et al., 2010), though this study represents the first direct assessment of this. Chasmer et al. (2011b) demonstrated that the total length of plateau

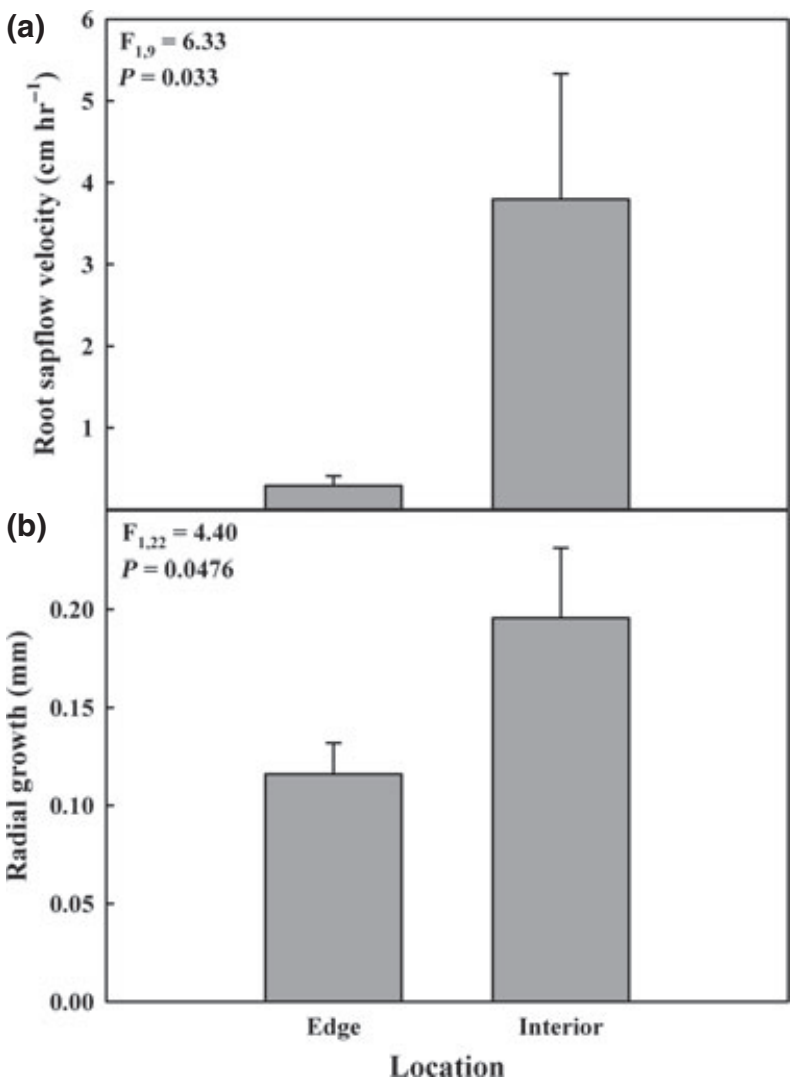

Fig. 5 Mean $( \pm 1 \mathrm{SE})$ maximum sap flow at the growing season peak (a) and tree radial growth, (b) for Picea mariana trees occurring at forest edges and in forest interiors. One-way analysis of variance results are presented for each metric in the respective panel.

edges increased through time as a consequence of permafrost loss, which in combination with this study suggests a potential fragmentation-related positive feedback on rates of permafrost thaw and forest loss. This response corresponds with previous examinations of edge effects on the degradation of forest fragments in a range of systems (Holdsworth \& Uhl, 1997; Harper \& Macdonald, 2002; Laurance et al., 2002). Such positive feedbacks of fragmentation on forest degradation are often a result of microenvironmental changes extending inward from the forest edge that negatively influence tree function and increase mortality (reviewed in Laurance et al., 2002; Kupfer et al., 2006) and in some instances exacerbate disturbances that then lead to enhanced tree mortality closer to forest edges and subsequent fragment degradation (e.g., Holdsworth \& Uhl, 1997). Although driven by changing environmental conditions at plateau edges that penetrate into the transitional forest, the mechanism here differs from that of previous studies of edge effects in more southerly locations where anthropogenic deforestation 


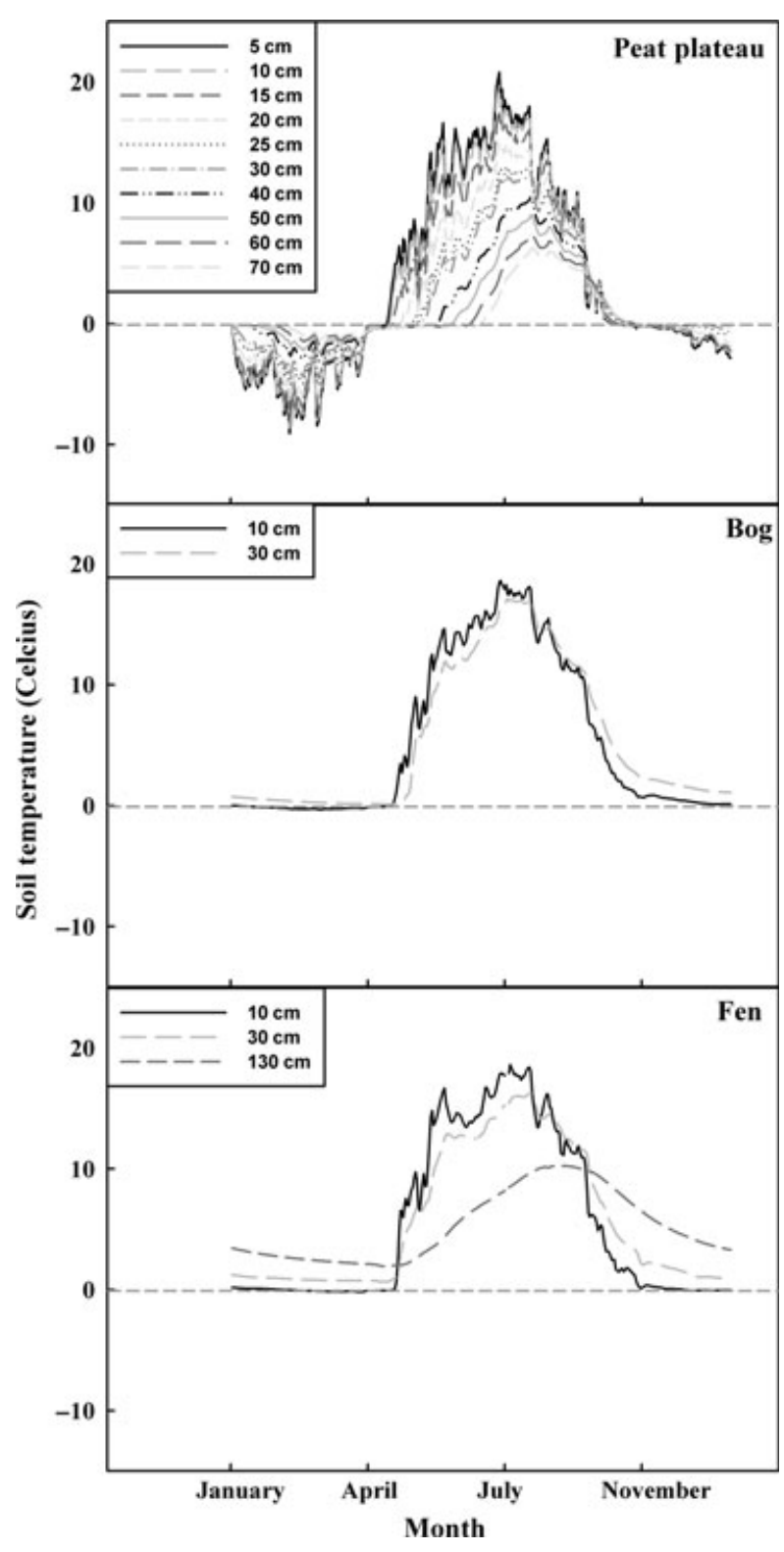

Fig. 6 Soil temperature profiles for organic soils on permafrost plateaus, flat bogs, and channel fens. These continuous data were collected during 2007 at $30 \mathrm{~min}$ intervals.

drives landscape fragmentation. Specifically, thermal erosion processes in the edge-influenced transitional forest lead to permafrost thaw-induced active layer thickening while contact between warm, saturated bog soils and adjacent peat plateaus contributes to lateral thaw processes. The outcome is ground surface subsidence, waterlogging, and reduced tree function leading to mortality (Camill et al., 2010) within the transitional forest. This effect has the potential to feed back on the thaw processes described above via reduced transpirational water loss, and increased incident radiation attributable to reduced tree cover in the transitional forest.

\section{Edge effects in permafrost plateau forests}

The relationship between rates of thaw and edge : area can be explained in terms of changing energy inputs and changing soil moisture conditions. Specifically, at plateau edges and within the transitional forest, reduced tree cover and associated reductions in $\mathrm{LAI}_{\mathrm{e}}$ increase the incident solar radiation on the ground surface compared with interior forest (Chasmer et al., 2011b). Furthermore, there are substantial differences in the soil thermal regimes of plateaus compared with bogs and fens (Fig. 6). Specifically, wetland areas have much warmer and more conservative thermal regimes at least in the upper $50 \mathrm{~cm}$ of peat than do the plateaus. With increasing depth in bogs and fens, the peat remains unfrozen even at the very end of the winter (Fig. 6). While temperatures in the upper $30 \mathrm{~cm}$ of peat on plateaus are relatively high during the growing season, they decrease rapidly with depth, whereas the wetland temperature profiles are much more constant with depth. O'Donnell et al. (2012) similarly found consistently warmer soil temperatures at greater depths in bogs in their transect-based measurements across collapse scar transitions. Thus, higher edge : area means both increased incident radiation and length of contact between (relatively) warm wetlands and deeper, cooler layers of the peat plateaus that provide the physical foundation for forests. In addition to the obvious implications of increased energy inputs, previous studies have demonstrated a strong link between soil moisture content and rates of permafrost thaw (e.g., Wright et al., 2009). Wetland habitats have greater soil moisture than do plateau habitats (Fig. $4 \mathrm{~b}$ ) and as the thermal conductivity of peat increases with water content, we can expect relatively high rates of horizontal conduction of energy from the relatively warm wetlands, across the wet boundary and into the plateaus. This horizontal energy flux augments the energy supplied by the downward vertical heat flux from the plateau ground surface. As a result, the rate of permafrost thaw at the plateau margins is relatively high compared with the thaw rate in the plateau interiors, where melt energy is supplied by the vertical flux alone. Even the vertical ground heat flux here is typically less than at the margins, as the ground surface of plateau interiors is relatively dry thereby insulating the permafrost while LAI is higher reducing solar energy inputs.

A thicker active layer that penetrates the plateau to between 10 and $15 \mathrm{~m}$ characterizes the transitional forest zone on the peat plateaus. The physiological changes of trees occurring at or near the edge of 
plateaus may contribute to this process. Specifically, because of the laterally extensive rooting system of P. mariana (J.L. Baltzer, personal observation and see Kajimoto et al., 2003 for Larix gmelinii rooting systems on permafrost), roots of many trees at or near the edge extend into the adjacent wetlands. Our sap flow measurements indicate that when this occurs, the roots effectively stop their water uptake function (Fig. 5a). This is a common response of roots to anoxic conditions that is mediated by the gating of water channel proteins (aquaporins) in roots during anoxia (Tournaire-Roux et al., 2003). Previous studies of $P$. mariana have demonstrated its limited potential to tolerate flooding either physiologically or through morphological modifications (e.g., adventitious root production) (Islam \& Macdonald, 2003, 2004), which corresponds to our findings of substantially reduced sap flow in waterlogged roots (Fig. 5a). In addition to the negative implications of reduced root function and water uptake on tree growth (Fig. 5b), this response of trees to edge conditions (thicker active layer and higher soil moisture transitioning into waterlogged conditions right at the plateau-bog interface) may be expected to feed back positively on high soil moisture contents at plateau edges that contribute to the thaw processes described above. Because of the strong water potential gradient across the soil-plant-atmosphere continuum and the large leaf surface area in trees, tree roots very effectively transport water from soils to the atmosphere thereby reducing soil moisture; forest soils are typically much drier than soils in open areas (Gray et al., 2002; Scharenbroch \& Bockheim, 2007). Thus, as P. mariana roots reduce or cease function within the transitional forest environment, this should result in further increases in soil moisture within this zone due to reduced total evapotranspiration. Indeed, significant negative relationships existed in our data between surface soil moisture and either fractional vegetation cover (linear regression; $\mathrm{r}^{2}=0.18, P<0.0001$ ) or $\mathrm{LAI}_{\mathrm{e}}$ $\left(\mathrm{r}^{2}=0.15, P<0.0001\right)$. Furthermore, we found that $\mathrm{LAI}_{\mathrm{e}}$ was reduced to a distance of ca. $5 \mathrm{~m}$ into the permafrost plateau forest (Fig. 4), which may also act to increase rates of active layer thaw near the plateau edges via increased incident radiation at the soil surface (Chasmer et al., 2011b). Previous studies of flood response in $P$. mariana include chlorosis and necrosis of needles thought to be attributable to reduced capacity for nitrogen uptake in flooded roots (Islam \& Macdonald, 2004) and would contribute to reduced $\mathrm{LAI}_{\mathrm{e}}$ and fractional cover in the transitional forest. This suggests that flooding impacts on $P$. mariana have the potential to feed back positively on both soil moisture and energy inputs with the transitional plateau edge environment.

\section{Implications and Conclusions}

As permafrost degrades, the amount of exposed forestwetland edge will increase (Chasmer et al., 2011b); thus, the present evidence of an important role of edge exposure and related edge effects in determining rates of thaw suggests an additional positive feedback in these systems that should contribute to increasing rates of permafrost thaw and forest loss. Enhancing our understanding of mechanisms contributing to differential rates of permafrost thaw and forest loss is critical for predicting future interactions between land surface processes and the climate system in high-latitude regions. This study provides evidence of both an accelerating rate of thaw and one that will continue to accelerate due to the increasing fragmentation associated with permafrost thaw. Canada's boreal peatlands form a broad swath through the middle of the boreal zone and $37 \%$ of this is underlain by permafrost (Tarnocai, 2006). As a consequence, the accelerating rates of thaw attributable to warming and fragmentation have the potential to convert large sections of this mid-boreal region from forest-wetland mosaic to unforested or sparsely treed, permafrost-free wetlands in a relatively short time frame (see Tarnocai, 2006; Quinton et al., 2011) and with important implications both for energy and carbon exchange. Findings from this study also highlight the need for greater complexity in the thermal models applied to permafrost thaw problems in northern peatlands (see Ling \& Zhang, 2003, 2004 for examples from Arctic regions) to advance our understanding of the patterns and mechanisms associated with this accelerating process.

\section{Acknowledgements}

Funding for this research was provided by the Natural Sciences and Engineering Research Council, the Canadian Federation for Climate and Atmospheric Science, and the Canadian Space Agency. We are grateful to R. Patankar and A. Downey installing sapflow sensors and A. MacLean for GPS data collection and processing. O. Sonnentag, A. Trant, and two anonymous reviewers provided feedback on an earlier version of the manuscript. We thank the Aurora Research Institute for their assistance in obtaining a research license (license number 15005). We also thank the Denedeh Resources Committee, Dehcho First Nations, Fort Simpson Métis Local \#52, Liidlii Kue First Nation and the Village of Fort Simpson for their support of ongoing research at Scotty Creek. In particular we thank Allan Bouvier and Allen Bonnetrouge of the Liidlii Kue First Nation, and Chief Stanley Sanguez of the Jean-Marie River First Nation for continued support. We also gratefully acknowledge the Wilfrid Laurier University - Government of the NWT Partnership 
Agreement for providing both infrastructural and logistical support to this study.

\section{References}

Anisimov O, Reneva S (2006) Permafrost and changing climate: the Russian perspective. Ambio, 35, 169-175.

Beilman DW (2001) Plant community and diversity change due to localized permafrost dynamics in bogs of western Canada. Canadian Journal of Botany, 79, 983-993.

Beilman DW, Robinson SD (2003) Peatland permafrost thaw and landform type along a climatic gradient. Proceedings of the 8th International Conference on Permafrost. Zurich, Switzerland, 2125 July, 2003. Vol 1. A.A, pp. 61-65. Balkema Publishers, Lisse, the Netherlands.

Camill P (1999) Patterns of boreal permafrost peatland vegetation across environmental gradients sensitive to climate warming. Canadian Journal of Botany, 77, 721-733.

Camill P (2005) Permafrost thaw accelerates in boreal peatlands during late-20th century climate warming. Climatic Change, 68, 135-152.

Camill P, Lynch JA, Clark JS, Adams JB, Jordan B (2001) Changes in biomass, aboveground net primary production, and peat accumulation following permafrost thaw in the boreal peatlands of Manitoba, Canada. Ecosystems, 4, 461-478.

Camill P, Chihara L, Adams B et al. (2010) Early life history transitions and recruitment of Picea mariana in thawed boreal permafrost peatlands. Ecology, 91, 448-59.

Chasmer L, Hopkinson C, Quinton W (2010) Quantifying errors in discontinuous permafrost plateau change from optical data, Northwest Territories, Canada: 1947-2008. Canadian Journal of Remote Sensing, 36, S211-S223.

Chasmer L, Hopkinson C, Petrone R, Quinton W (2011a) Fusion of airborne LiDAR and WorldView-2 MS data for classification of depth to permafrost within Canada's subArctic. Proceedings of SilviLaser 2011, 11th International Conference on LiDAR Applications for Assessing Forest Ecosystems, pp. 1-7. University of Tasmania, Australia, 16-20 October 2011.

Chasmer L, Quinton W, Hopkinson C, Petrone R, Whittington P (2011b) Vegetation canopy and radiation controls on permafrost plateau evolution within the discontinuous permafrost zone, Northwest Territories, Canada. Permafrost and Periglacial Processes, 22, 199-213.

Christensen TR, Johansson T, Akerman HJ et al. (2004) Thawing sub-arctic permafrost: effects on vegetation and methane emissions. Geophysical Research Letters, 31, L04501.

Drew MC (1997) Oxygen deficiency and root metabolism: injury and acclimation under hypoxia and anoxia. Annual Review of Plant Physiology and Plant Molecular Biology, 48, 223-250.

Environment Canada (2007) Canadian Climate Normals 1971-2000. Available at http://climate.weatheroffice.gc.ca/climate_normals/results_e.html (accessed on 4 July 2013).

Ewers RM, Didham RK (2008) Pervasive impact of large-scale edge effects on a beetle community. Proceedings of the National Academy of Sciences of the United States of America, 105, 5426-5429.

Frolking S, Talbot J, Jones MC, Treat CC, Kauffman JB, Tuittila E-S, Roulet N (2011) Peatlands in the Earth's 21st century climate system. Environmental Research, 19, 371-396.

Gorham E (1991) Northern peatlands: role in the carbon cycle and probably response to climatic warming. Ecological Applications, 1, 182-195.

Gray AN, Spies TA, Easter MJ (2002) Microclimatic and soil moisture responses to gap formation in coastal Douglas-fir forests. Canadian Journal of Forest Research, 32, 332-343.

Harper KA, Macdonald SE (2002) Structure and composition of edges next to regenerating clear-cuts in mixed-wood boreal forest. Journal of Vegetation Science, 13, 535 546

Harper KA, Macdonald SE, Burton PJ et al. (2005) Edge influence on forest structure and composition in fragmented landscapes. Conservation Biology, 19, 768-782.

Heginbottom JA (2002) Permafrost mapping: a review. Progress in Physical Geography, 26, 623-642.

Holdsworth AR, Uhl C (1997) Fire in Amazonian selectively logged rain forest and the potential for fire reduction. Ecological Applications, 7, 713-725.

Islam MA, Macdonald SE (2003) Responses of black spruce (Picea mariana) and tamarack (Larix laricina) to flooding and ethylene. Tree Physiology, 23, 545-552.

Islam MA, Macdonald SE (2004) Ecophysiological adaptations of black spruce (Picea mariana) and tamarack (Larix laricina) seedlings to flooding. Trees - Structure and Function, 18, 35-42.
Jorgenson MT, Osterkamp TE (2005) Response of boreal ecosystems to varying modes of permafrost degradation. Canadian Journal of Forest Research, 35, 2100-2111.

Jorgenson MT, Shur YL, Pullman ER (2006) Abrupt increase in permafrost degradation in Arctic Alaska. Geophysical Research Letters, 33, L02503.

Jorgenson MT, Romanovsky V, Harden J et al. (2010) Resilience and vulnerability of permafrost to climate change. Canadian Journal of Forest Research, 40, 1219-1236.

Kajimoto T, Matsuura Y, Osawa A, Prokushkin AS, Mark A, Abaimov AP (2003). Root system development of Larix gmelinii trees affected by micro-scale conditions of permafrost soils in central Siberia. Plant and Soil, 255, 281-292.

Kozlowski TT (1982) Water supply and tree growth Part II. Flooding. Forestry Abstracts, 43, 145-161.

Kupfer JA, Malanson GP, Franklin SB (2006) Not seeing the ocean for the islands: the mediating influence of matrix-based processes on forest fragmentation effects. Global Ecology and Biogeography, 15, 8-20.

Kwong YTJ, Gan TY (1994) Norhtward migration of permafrost along the Mackenzie highway and climatic warming. Climatic Change, 26, 399-419.

Laurance WF, Lovejoy TE, Vasconcelos HL et al. (2002) Ecosystem decay of Amazonian forest fragments: a 22-year investigation. Conservation Biology, 16, 605-618.

Ling F, Zhang T (2003) Numerical simulation of permafrost thermal regime and talik development under shallow lakes on the Alaskan Arctic Coastal Plain. Journal of Geophysical Research, 108, doi: 10.1029/2002JD003014.

Ling F, Zhang T (2004) Modeling study of talik freeze-up and permafrost response under drained thaw lakes on the Alaskan Arctic Coastal Plain. Journal of Geophysical Research, 109, doi: 10/1029/2003 JD003886.

Lloyd AH, Bunn AG (2007) Responses of the circumpolar boreal forest to 20th century climate variability. Environmental Research Letters, 2, 045013.

McGarigal K and Marks BJ (1995). FRAGSTATS: Spatial pattern analysis program for quantifying landscape structure. General Technical Report PNW-GTR-351. US Department of Agriculture, Forest Service, Pacific Northwest Research Station.

O'Donnell JA, Jorgenson MT, Harden JW, McGuire AD, Kanevskiy MZ, Wickland KP (2012) The effects of permafrost thaw on soil hydrologic, thermal, and carbon dynamics in an Alaskan peatland. Ecosystems, 15, 213-229.

Payette S, Delwaide A, Caccianiga M, Beauchemin M (2004) Accelerated thawing of subarctic peatland permafrost over the last 50 years. Geophysical Research Letters, 31, L18208.

Quinton WL, Baltzer JL (2013) The active-layer hydrology of a peat plateau with thawing permafrost (Scotty Creek, Canada). Hydrogeology Journal, 21, 201-220.

Quinton WL, Hayashi M, Chasmer LE (2009) Peatland hydrology of discontinuous permafrost in the Northwest Territories: overview and synthesis. Canadian Water Resources Journal, 34, 311-328.

Quinton WL, Hayashi M, Chasmer LE (2011) Permafrost-thaw-induced land-cover change in the Canadian subarctic: implications for water resources. Hydrological Processes, 25, 152-158.

R Development Core Team (2011) R: A language and environment for statistical computing. R Foundation for Statistical Computing, Vienna, Austria. ISBN 3-900051-07-0, Available at: http:/ /www.R-project.org/ (accessed on 8 July 2011).

Scharenbroch BC, Bockheim JG (2007) Impacts of forest gaps on soil properties and processes in old growth northern hardwood-hemlock forests. Plant and Soil, 294, 219-233.

Smith SL, Burgess MM, Riseborough D, Nixon FM (2005) Recent trends from Canadian permafrost themal monitoring network sites. Permfrost and Periglacial Processes, 16, 19-30.

Soja AJ, Tchebakova NM, French NHF et al. (2007) Climate-induced boreal forest change: predictions versus current observations. Global and Planetary Change, 56, 274-296.

Speer JH (2010) Fundamentals of tree-ring research. The University of Arizona Press, Tuscan

Tarnocai C (2006) The effect of climate change on carbon in Canadian peatlands. Global and Planetary Change, 53, 222-232.

Tarnocai C, Canadell JG, Schuur EAG, Kuhry P, Mazhitova G, Zimov S (2009) Soil organic carbon pools in the northern circumpolar permafrost region. Global Biogeochemical Cycles, 23, GB2023.

Thie J (1974) Distribution and thawing of permafrost in the sourthern part of the discontinuous permafrost zone in Manitoba. Arctic, 27, 189-200.

Tournaire-Roux C, Sutka M, Javot H et al. (2003) Cytosolic pH regulates root water transport during anoxic stress through gating of aquaporins. Nature, 425, 393-397.

Turetsky MR, Wieder RK, Vitt DH, Evans RJ, Scott KD (2007) The disappearance of relict permafrost in boreal North America: effects of peatland carbon storage and fluxes. Global Change Biology, 13, 1922-34.

Turetsky MR, Kane ES, Harden JW, Ottmar RD, Manies KL, Hoy E, Kasischke ES (2011) Recent acceleration of biomass burning and carbon losses in Alaskan forests and peatlands. Nature Geoscience, 4, 27-31. 
834 B ALTZER et al.

Wright N, Hayashi M, Quinton WL (2009) Spatial and temporal variations in active layer thawing and their implication on runoff generation in peat-covered permafrost terrain. Water Resources Research, 45, W05414.

Yoshikawa K, Hinzman LD (2003) Shrinking thermokarst ponds and groundwater dynamics in discontinuous permafrost near Council, Alaska. Permafrost and Periglacial Processes, 14, 151-60.
Zhang Y, Chen JM, Miller JR (2005) Determining digital hemispherical photograph exposure for leaf area index estimation. Agricultural and Forest Meteorology, 13, 166-181.

Zoltai SC (1993) Cyclic development of permafrost in the peatlands of northwestern Alberta, Canada. Arctic, Antarctic, and Alpine Research, 25, 240-246. 